\title{
Um romance para Riobaldo ou os romances do Brasil
}

\section{Vera Haas*}

\begin{abstract}
Resumo: A idéia de agon e de diálogo entre obras da literatura brasileira deve orientar a interpretação de nossa historiografia no que se refere à produção de escritores como José de Alencar, Guimarães Rosa e Machado de Assis. A mudança de perspectiva no que se refere à aceitação de um sistema literário forjado pela semelhança entre autores demonstra que a predileção autoral e crítica por romances regionalistas, freqüentes na história da literatura brasileira, só pode ser efetuada por meio de uma perspectiva pósmoderna. A compreensão da história da literatura brasileira passa pelo deciframento de um sistema forjado pela dessemelhança.
\end{abstract}

Palavras-chave: historiografia; museografia, Brasil; personagem; narrador.

\begin{abstract}
The idea of agon and a dialogue between literary works of Brazilian literature must be the guidelines for our historiography concerning the production of authors such as José de Alencar, Guimarães Rosa and Machado de Assis. The change of perspective concerning the acceptance of a literary system based on similitude between authors demonstrates that the preference, both of authors and of critics, frequently given to regionalist novels, can only be carried out from a post-modern perspective. The understanding of the history of Brazilian literature must take into consideration the deciphering of a system based on dissimilitude.
\end{abstract}

Keywords: historiography; museography; Brazil; character; narrator.

Identidade, memória e narração formam uma tríade constante na literatura brasileira. Constante e algo insistente, motivos pelos quais ainda merece nossa atenção. Para nos determos mais uma vez sobre essa questão, consideraremos duas obras que são, atualmente, marcos distintos da história da literatura do Brasil: $O$ Guarani $(O G)$ e Grande sertão: veredas $(G S V)$. Enquanto Alencar é colocado como o escritor que inicia uma linhagem de romances ocupados em fundar o Brasil e sua brasilidade, Rosa é visto como o escritor que ultrapassa o lugar comum em uma linhagem que se esforçava por manter vivo o regionalismo como estética definidora da nação. Do indianismo e regionalismo alencarianos, chegamos ao superregionalismo (ou a nova narrativa épica) rosiano. Nesse trabalho, porém, recusamos a narração histórica redundante em historiografias e, conseqüentemente, aceita por alguma crítica literária: a linearidade da leitura e da exposição. A presente análise propõe um olhar que, independente do ponto de partida, considere o deslocamento dos sentidos produzidos por narrativas organizadas em torno da tríade supracitada, de modo a evidenciar olhares

\footnotetext{
* Ms. Literatura Brasileira, professora do Curso de Letras e da Pós-Graduação na Universidade do Vale do Rio dos Sinos (UNISINOS)
} 
divergentes e a (re)apropriação de questões que, tratadas como subalternas, demonstraram ser o fulcro sobre o qual se constroem textos literários que se ocupam com nossa identidade.

Ao refletir sobre as categorias narrativas por meio das quais os textos se iluminam reciprocamente, propomos também uma problematização da história da literatura brasileira. Esta virá imbricada àquelas, subterrânea, mas não menos importante. Pontuaremos uma concepção linear na exposição da literatura brasileira, bem como a confirmação sistemática de cânones que permanecem isolados no panteão brasileiro, ou seja, em solilóquio. Se consultarmos historiadores e críticos como Alfredo Bosi (2006) e Luciana Stegagno-Picchio (2004), descobriremos destaques para Clarice Lispector e Guimarães Rosa, por exemplo, lidos como apêndices de seu tempo, e para Machado de Assis, uma ilha na literatura do Brasil, segundo Stegagno-Picchio. Por outro lado, a concepção de cânone como ágon, como defende Harold Bloom (2001), ou ainda como memória estética, como demonstram Bloom e Auerbach (1976), em O cânone ocidental e Mimesis, respectivamente, e a preferência nacional por romances realistas naturalistas, questionada por Süssekind (1984), em Tal Brasil, qual romance?, podem iluminar a leitura de obras fundamentais para a literatura brasileira. As reflexões de Bloom e Auerbach demonstram que a influência entre obras ocorre, mesmo quando o resultado estético atinge a torção de metáforas que desfiguram o diálogo existente entre os autores. Süssekind endossa essa posição ao questionar a relevância de um sistema literário que reafirma o valor de obras que se alinham pela similaridade estética, ressaltando um conjunto de obras em absoluta solidão formal e temática.

Para melhor movimentar os textos em questão, consideraremos a narrativa de Ginzburg (2006) sobre as idéias que condenaram o moleiro Menocchio e as observações de Castro (1992) relativas à autoridade museográfica e seu papel social. A utilização desses textos servirá para levantar uma relação proveitosa entre a narração da história da literatura, da história das idéias e da história de objetos culturais, a fim de rastrear noções como hegemonia, autoridade e representação de identidade. Poderemos verificar como afirmações hegemônicas tornam-se autoritárias e acabam por obscurecer relações que ampliariam a compreensão de uma identidade cultural elaborada via romance.

Se recusarmos um olhar cuja expectativa é a descoberta de uma identidade coesa, indissociável, capaz de integrar a paisagem social exterior a sua intimidade, se partirmos do olhar de um sujeito fragmentado, cujas identidades podem multiplicar-se sem a necessidade de que haja unidade ou estabilidade, a ilha a que se refere Stegagno-Picchio e os destaques recebidos por Rosa e Lispector passam a interagir entre si e com as demais obras, na medida em que o conjunto das identidades produzidas por textos ficcionais não necessita de um norte 
comum ou de um sistema de representações que tenha por objetivo a estabilidade de uma única identidade. Nesse sentido, Rosa cria uma identidade que pode ou não ecoar em Alencar, e ambos apresentam-se como fragmentos esparsos de uma identidade que não ocupou apenas nossos escritores, mas preocupa até hoje aqueles que se dedicam à historiografia e à crítica literária - provavelmente em busca de uma identidade estável, una. Talvez, a possibilidade de compreendermos esse retorno constante à afirmação de uma identidade só possa encontrar algum êxito se pensarmos que a narração de nosso sistema literário requer um olhar pósmoderno, capaz de ler nos fragmentos a única identidade possível.

A colonização desagregou as culturas nativas, violou as culturas africanas, exigiu adaptações aos portugueses e imigrantes. As profundas diferenças sociais criaram religiões paralelas e relações de dependência ou clientelismo. O saldo é uma identidade fragmentada, móvel, que se mostra capaz de incorporar até mesmo o que não lhe é peculiar. A rigidez dos lugares sociais contrasta com alternativas para a convivência entre classes e culturas. $\mathrm{O}$ Museu, a História e a Narrativa literária apresentam-se como narradores de memórias sociais. O modo como essas áreas do conhecimento interpretam e articulam os símbolos de nossa cultura evidencia-se na forma de sua narração.

Gostaríamos de pensar a exposição da história da literatura considerando a museografia e a expografia. Ao refletir sobre a museificação do objeto, Castro reconhece que o senso comum atribui aos museus uma relação com o que é autêntico, original, e precisa ser preservado como memória dos testemunhos materiais/imateriais que identificam certa camada social. Castro explica que a articulação narrativa do objeto museal é responsável por sua interpretação por parte dos freqüentadores do museu. A museografia e a expografia são as formas pelas quais podemos compreender a narração museológica.

A autora usa Le Goff para esclarecer o conceito de museu e a importância das narrativas museológicas e expográficas. Para Le Goff, a nação tem no historiador seu biógrafo; para Castro, por analogia, o museu seria um dos mais credenciados narradores de uma nação. Importa também a elaboração mítica de memória demonstrada por Jean-Pierre Vernant: a rememoração do passado tem como contrapartida o esquecimento do presente, um “deciframento do invisível” (VERNANT apud CASTRO, 1992, p.4).

A disposição dos objetos, a organização produzida para narrar a identidade cultural pretendida pelo museu e pela exposição, funciona como um discurso que articula diferentes objetos para a produção de sentidos. O museu evidencia a maleabilidade de seus discursos mediante o remanejo dos objetos ora expostos e acrescidos de peças retiradas dos porões, ora rearticulados para determinada ação comemorativa. Essa possibilidade de remanejo constante 
demonstra que a narração expográfica opera com memórias e esquecimentos. Voluntários ou não, memórias e esquecimentos passam a constituir a narração da identidade articulada pela exposição. Nesse sentido, a expografia apresenta sempre um discurso autoritário e excludente por meio do qual o museu constitui um sistema de signos, um constructo de significados que oferece à nação uma imagem de si.

A narração dos museus, pela apresentação de bens culturais materiais e imateriais em uma articulação dada, lembra a apresentação que Ginzburg oferece em $O$ queijo e os vermes. Em sua narrativa, Ginzburg redesenha a história de Menocchio. O historiador rearticula discursos diferentes - bens imateriais - , coloca-os imbricados a fim de demonstrar aquilo que a Inquisição não podia compreender. Mais que isso, evidencia o modo pelo qual Menocchio rearticulou suas leituras, rastreando conceitos ou trechos expressivos de livros da época, bem como imagens recorrentes em narrativas populares presentes no imaginário da cidade.

O historiador cria uma voz narrativa que não sinaliza ao leitor seu ponto de chegada, mas constrói, paulatinamente, os fios de sentido por meio dos quais podemos compreender a situação do moleiro, da comunidade e da Inquisição. Os discursos aparentemente incongruentes, a dificuldade de comunicação entre o moleiro e a Inquisição e a lucidez do leitor ávido demonstram uma identidade formada por contradições e idéias em gestação, bem como a capacidade de articular imagens e conceitos opostos sob um raciocínio que ainda vincula imagens e resíduos da narrativa oral a conceitos de textos escritos presentes na memória de Menocchio. Ginzburg dá-nos acesso a livros de ampla circulação, a idéias proibidas - e, por isso mesmo, reservadas a poucos textos, esses conhecidos pela própria Inquisição - e à posição do moleiro na comunidade em que vivia. A articulação entre essas variantes permite-nos conhecer a complexidade da figura de Menocchio, seus discursos, as influências que recebeu, a posição de prestígio dos moleiros de sua época. Chama nossa atenção o modo pelo qual Ginzburg organiza sua narração, ora relatando a vida na aldeia, ora alertando para a cultura da época, ora narrando as conversas do moleiro, ora comentando a produção cultural.

O historiador define os elementos que formarão a narrativa e a forma de expor esses elementos para a composição de uma narrativa que atinge uma identidade individual sem deixar de vislumbrar uma identidade coletiva. A forma de apresentação ganha uma aparência que, inicialmente, assemelha-se às histórias de Mennochio. Há uma oscilação entre a narração propriamente dita e os comentários que o historiador insere acerca do narrado. Os comentários são rápidos, por vezes até sucintos, como no trecho 24 ; outras vezes um pouco mais extensos, fazendo uma revisão do olhar do historiador e da atitude deste em relação a 
aspectos de produção cultural que exigem uma hegemonia, como é o caso do trecho 61 . Gradualmente, surge o questionamento relativo ao manejo dos bens imateriais manuseados pela história, bem como a exigência de uma história das idéias descortinada sob o viés da hegemonia. Essa hegemonia nos impede de perceber outras concepções de mundo que, por vezes, acabam constituindo uma hegemonia tardia. Supreendemo-nos, então, pois sentimos dificuldades em rastrear a origem de determinada idéia ou conceito.

As reflexões até aqui desenvolvidas funcionam como um constructo para que possamos apresentar um conjunto de asserções a respeito da literatura, e também relativo à literatura brasileira, a fim de repensar nossa historiografia no que se refere à ausência de relação entre obras consideradas canônicas pela inovação estética e obras que, apesar de ocuparem uma posição de reconhecimento, acabaram rotuladas como obras fundantes, sim, mas ultrapassadas e esvaziadas de contribuição para as conquistas de escritores posteriores. A História da Literatura é uma área do conhecimento que partilha formas de narração e exposição similares àquelas usadas pela História e pela Museologia, como procuramos mostrar. Também a historiografia de nossa literatura coloca-se como a narração de obras fundamentais - bens imateriais postos em livros, os bens materiais - para a constituição da literatura da nação e como a guardiã da memória das obras que procuraram definir ou desenhar o perfil do povo brasileiro, a sua brasilidade. Na história de nossa literatura, somos instigados a buscar uma imagem de nós mesmos, de nossa pátria.

No entanto, o problema exposto inicialmente advém de um modo de exposição da história da literatura que se compromete com uma visão permeada pela idéia de hegemonia, ou seja, a afirmação de uma produção interessante de romances, dentre os quais os de caráter regionalista, esses, sim, comprometidos com a firmação da identidade nacional. A parafernália de obras narrativas ficcionais que pulverizam nossa história da literatura acaba por jazer ao lado das obras regionalistas, assim como certos cânones permanecem uma ilha. Esses fragmentos parecem uma colcha de retalhos: por meio da narração que se ergue dos retalhos, deveríamos reconhecer nossa memória e uma narração historiográfica que precisa valorizar a contradição e os vazios que preenchem uma visão que se quer coesa e hegemônica - um "deciframento do invisível” -, partes constitutivas da narração da identidade pósmoderna de uma nação recente. Nesse sentido, ao considerar uma das formas narrativas mais desenvolvidas no Brasil, o romance, importam-nos uma certa linhagem de narradores, dos quais passamos da memória articulada via romance histórico para a confissão, e uma linhagem de personagens, dos quais sublinhamos a passagem de certos personagens secundários à categoria de protagonistas. O deslocamento de personagens articula narração e 
tema, evidenciando o lugar de onde falam os personagens e as questões que ganham destaque em nossa literatura.

Para prosseguir, precisamos observar que, cem anos antes da publicação de $G S V$, José de Alencar critica o poema épico de Gonçalves de Magalhães, afirmando que o gênero épico clássico não serve como opção estética para a representação do Brasil. Alencar reclama por uma nova forma de poesia narrativa: Escreveríamos um poema, mas não um poema épico; um verdadeiro poema nacional, onde
tudo fosse novo, desde o pensamento até a forma, desde a imagem até o verso. A forma com
que Homero cantou os gregos não serve para cantar os índios; o verso que disse as desgraças
de Tróia e os combates mitológicos não pode exprimir as tristes endeixas do Guanabara, e as
tradições selvagens da América. Porventura não haverá no caos incriado do pensamento
humano uma nova forma de poesia, um novo metro de verso?

(ALENCAR apud BARBOSA; BELETTI, 2006)

Quer o escritor romântico uma obra que valorize a cultura indígena e que seja adequada à expressão da nação, cujo projeto literário vai construir nos anos seguintes por meio de seus romances. A colocação de Alencar não é ingênua, ele mesmo confessa ter lido Walter Scott, além de uma série de relatos de viagens pelo Brasil. Com Alencar, a idéia romântica do romance de fundação ganha fôlego e sistema, uma vez que o escritor procura, com seus vários romances, desenhar o país em que vive, recriando as sociedades indígenas, a corte carioca, os aventureiros que desbravaram as terras desconhecidas e os tipos culturais de diversas regiões.

Em maio de 1956, Guimarães Rosa publica um romance, Grande sertão: veredas, obra literária que viria alterar a história da literatura brasileira e uma das vertentes mais profícuas da literatura de representação nacional, o regionalismo. A revolução representativa causada por $G S V$ é consenso na crítica literária brasileira. Cem anos depois da declaração do criador de Peri e Iracema, Rosa propõe, sim, um romance, mas seus personagens trilham caminhos em busca da imagem de um Brasil que não recuse a sua história, a história de seu povo. E, diferente de Alencar, o escritor mineiro opta por um romance confessional.

Para esse trabalho, apresentaremos um cotejo entre os personagens Isabel e Peri, de $O G$, e Riobaldo, de GSV. Sempre que necessário, comentaremos os demais personagens, considerando as relações estabelecidas nos romances. As obras relacionam-se com a atitude de rememoração ou de expressão de uma memória perpetuadora (BENJAMIN, 1994, p.211), característica da narrativa romanesca: trata-se da atitude de lembrar novamente. O primeiro romance representa a recuperação de um passado histórico, o segundo, apresenta uma voz confessional proveniente de um passado histórico. Essas escolhas de narrador são importantes 
para a compreensão dos personagens e do deslocamento de sentidos nas figuras em que nos fixamos para a presente apreciação.

Os personagens mais complexos do romance de Alencar são, certamente, Isabel e Loredano, ou seja, aqueles que não protagonizam o romance, antes compõem a gama de antagonistas da trama. Instáveis, sujeitos a bons e maus sentimentos, capazes de temer e de amar, esses personagens colocam em cena problemas cruciais como o não-pertencimento de Isabel, mestiça que não é escrava e nem parte da família, mulher destituída de família, de dote e, portanto, de direito ao amor e ao casamento. Embora seja um personagem de segundo plano no romance de Alencar, uma vez que sua importância se deve ao fato de antagonizar com Cecília pelo amor de Álvaro, Isabel parece indicar uma tradição literária de personagens símbolo do homem/mulher brasileiro/a destituídos de direitos - a começar pelo reconhecimento paterno -, freqüentemente relegados a uma posição de subserviência e dependência.

O narrador onisciente revela-nos os pensamentos obscuros e os anseios juvenis da personagem. A insegurança, o desejo contido, a raiva silenciosa pelo destino da mãe fornecem verossimilhança à personagem, permitindo que um pano de fundo histórico se coloque ao lado das proezas de Peri e da altivez de D. Antônio de Mariz. Somos convidados à realidade histórica principalmente por ocasião da confissão do fidalgo ao filho e a D. Álvaro, cena possível pela voz onisciente que desvela a consciência de D. Antônio. Sob o receio de magoar a esposa, o fidalgo reconhece a paternidade de Isabel, recorda comovido o destino da mãe da jovem, e mantém-se na posição que ocupa: Isabel será sempre sua sobrinha, nessa condição deve ser protegida pelos dois rapazes.

Em uma sociedade patriarcal e rígida em seus costumes, pois cada um conhece bem o lugar que ocupa, Isabel permanece destituída de um pai e de tudo o que faria dela uma moça aceitável para a sociedade da época. Soma-se a esse fato seu tipo físico, segundo o narrador, de uma típica beleza brasileira, que não impede a inveja de Isabel em relação à beleza suave de Cecília. O mesmo narrador caracteriza a figura de Isabel com adjetivos como malícia, languidez, lábios desdenhosos, sorriso provocador. A jovem mestiça aparece como herdeira de uma situação trágica, pois sua beleza desperta o desejo dos homens, mas não tem dote a oferecer, não tem um nome paterno para apresentar, não tem lugar em uma sociedade que ainda recusa o brasileiro mestiço.

Mas Isabel é também astuta, maliciosa, sabe jogar para atingir seus fins. Madura em relação ao mundo que a cerca, conhece o papel que lhe permitem desempenhar na casa dos Mariz. Dissimula seus sentimentos quando julga necessário, quer para se proteger, quer por 
amor à jovem prima ou por amor a Álvaro. Tudo coloca Isabel à margem da sociedade da época, tanto a ausência de referenciais sociais e de origem quanto a independência emocional que adquire e com a qual rege seus sentimentos e atitudes. O final que Alencar destinou a Isabel e Álvaro condiz com a situação vivida pelos enamorados.

Do mesmo modo, Riobaldo é um menino sem pai, pobre, herdeiro de uma mãe que erra entre os homens, o pouco trabalho e a mendicância para sobreviver. Riobaldo, porém, reconhece que vive em um mundo em que o comum é filho sem pai. Os pais viajam, viram jagunços, enfim, saem pelo mundo. As mães ficam com seus filhos. Mais tarde, suspeitando ser Selorico seu pai, Riobaldo renega essa paternidade e parte para construir uma vida de aventuras na jagunçagem. O afilhado/filho segue em busca da vida admirada por Selorico Mendes, um fazendeiro contador de histórias e admirador dos jagunços.

O que vemos em $G S V$ é a trajetória do filho da Bigri, herdeiro de uma grande pobreza, que se transforma em professor e, logo, em Riobaldo Tatarana, depois, em chefe Urutu Branco, e, finalmente, em fazendeiro contador de histórias. Em todas essas transformações, permanecem as angústias de quem não sabe ao certo quem é. Afinal, Riobaldo é filho de uma mãe sem marido, jagunço com um sentir afetuoso pelo companheiro Reinaldo-Diadorim, sentimento que lhe causa ao mesmo tempo bem-estar e aversão e, ainda, admirador do Hermógenes a quem também odeia, e de Zé Bebelo, de quem desconfia. Riobaldo está sempre entre pólos aparentemente opositivos, oscilando entre perspectivas que exigem uma escolha. E a escolha não se apresenta clara nem mesmo excludente de seu contrário.

Como Isabel, o núcleo familiar a que pertence Riobaldo carece da figura paterna. Também como Isabel, Riobaldo dissimula sentimentos e falas de acordo com seus interesses. Entretanto, cabe a Riobaldo a "sorte" de viver em um sertão em que os pais partem e abandonam suas famílias e de experienciar um momento de transição na história jagunça, obtendo destaque para sua capacidade de articular discursos e idéias no exercício de diferentes papéis sociais. Cabe a Riobaldo sobreviver às suas angústias existenciais e ao amor por Diadorim.

O universo a que pertence Isabel, apesar de colocado no interior do Brasil, mantém normas de conduta e de civilização adequadas ao perfil dos nobres portugueses. A rigidez das posições sociais aparece quebrada apenas por dois detalhes: a aceitação de Isabel no convívio familiar, ainda assim como uma espécie de agregada, e a permanência de Peri entre os brancos, presença associada a valores encarnados pelo protagonista e reconhecidos por Dom Antônio, pois, demonstra-nos Santiago (1982), assim como o fidalgo representa o rei de Portugal em terras brasileiras, Peri é um rei naquelas matas. Isabel, dependente da boa 
vontade da família Mariz, ocupa um lugar socialmente frágil. A qualquer momento a jovem pode ser deslocada da posição que ocupa, ao bel prazer dos poderosos. Em relação à família, o afeto de Cecília é sua única certeza. Peri, morador das matas, embora tenha abandonado sua tribo, ainda pertence a um lugar, pode ir e vir como desejar. A escolha de ficar ao pé de Ceci é sua, assim como a aceitação dos percalços que isso traz, consciência que reforça a simpatia do narrador por seu protagonista.

O narrador onisciente revela-nos um mundo sem horizontes para Isabel; ao mesmo tempo, desvela uma atitude de simpatia por Cecília e de admiração por homens cuja moral não se corrompe nem se modifica, como ocorre com Peri e, em certa medida, se considerarmos a paternidade de Isabel, com Dom Antônio de Mariz. A inteireza dos protagonistas mostra a concepção de sujeitos coesos, imutáveis em sua essência, mesmo com o desenrolar do enredo. Nesse mundo, Isabel é vista como uma personagem fraca, sem perspectivas, carente de dignidade, uma vez que as oscilações vividas pela jovem provêm da precária posição que ocupa na casa, ou seja, evidenciam mudanças de personalidade, inseguranças e uma atitude que depende de fatores externos, não de uma identidade dada a priori ou construída na relação com a família de Cecilía.

O narrador personagem Riobaldo não apenas retoma o problema do nãopertencimento, como desloca essa questão para a multiplicidade de papéis que desempenha no romance. Sem pai em um mundo regido pela força masculina, a voz de Riobaldo não apresenta a dureza inteirada do narrador de Alencar, mas a dubiedade, o adequar-se a situações imprevistas ou difíceis de ultrapassar, as circunvoluções de um olhar reflexivo e sempre atento ao ir e vir das pessoas e das coisas. Herdeiro da Bigri e de seus vários esforços para manter-se, Riobaldo é flexível num mundo cuja transição exige maleabilidade. O sertão dos jagunços está se modificando, a política citadina começa a entrar no mundo sem lei, a astúcia e a mobilidade discursiva são atributos necessários a esses guerreiros, como o foram para Odisseu.

Riobaldo ocupará uma posição ambígua em relação aos parceiros da Bigri e por ocasião da morte da mãe. Levado ao convívio de Selorico Mendes, sente-se mal na fazenda do padrinho, agregado sem o ser de fato, desejoso de outra vida, aliás, encantado como Selorico com as aventuras dos bandos de jagunços. Mas, também após reunir-se aos jagunços, o protagonista continua a perceber-se deslocado, fora de lugar. Sua habilidade discursiva, a capacidade para reparar nas minúcias e a complexidade que atribui a fatos que passam despercebidos pelos outros companheiros inquietam Riobaldo. Nem mesmo a mudança de nomeação já referida oferece ao sertanejo a tranqüilidade de uma identidade una, coesa, em 
consonância com a posição que ocupa e o lugar em que está, quer em um determinado momento de sua vida, quer enquanto narra suas memórias ao senhor. O tom confessional da narrativa romanesca revela a constante sensação de não-pertencimento sofrida pelo narrador protagonista.

A atitude de recuperar por meio da narração um fio que reúna as partes de sua história, formando um todo coeso, esbarra nos sentimentos do velho fazendeiro, na percepção de um estar fora de lugar, mesmo agora, pois sente que pode ter perdido algo em sua vida, mas não sabe o quê. Essa angústia o deixa em uma situação novamente ambígua, porque, para viver plenamente, Riobaldo precisa vasculhar seu passado na busca de um sentido supostamente perdido. O deslocamento vivido pelo sertanejo parece alçar-se a sua voz, de modo que a sensação de não-pertencimento, de estar sempre deslocado, acompanha o modo como organiza a imagem de si mesmo.

À linearidade e à imutabilidade valorativa da voz que narra em $O G$, alia-se a idéia de integridade moral, esta presente por meio de personagens que representam uma espécie de essência fixa ao lado de um lugar social bem marcado. Mas, às oscilações presentes na narração de Riobaldo, precisamos lançar um olhar mais cuidadoso. Ao internalizar o sertão, Riobaldo procura identificar-se com o lugar em que sempre viveu. E sua confissão reside nisso: a impossibilidade de internalizar o sertão, a certeza de um sentimento de nãopertencimento a acompanhar suas andanças, inclusive a vida de fazendeiro e sua narração. $\mathrm{O}$ desenho do ícone do infinito ao fim do romance corrobora com essa sensação, pois remete a uma procura que não se esgota, afirmando uma narração contínua.

A representação alcançada por Rosa no $G S V$ indica a busca de uma identidade, motivo que resulta na confissão de um sistemático estar fora do lugar. Para Riobaldo, não importa a diversidade de transformações pelas quais passou e nem os papéis sociais que desempenhou. O que Riobaldo busca é unificar tudo isso em um sentido coeso, único. Ao final, a confissão de que o humano se dá na travessia reafirma a identidade, possível apenas no reconhecimento dos vários papéis desempenhados, nem sempre por escolha, mas capazes de apresentar a multiplicidade de fragmentos que compõem a história do homem brasileiro, do sertão à civilização urbana, da força violenta à lei escorregadia e enganosa.

Em Rosa, mantém-se a orfandade familiar e a dependência já vistas em Alencar. Mas a antagonista Isabel ganha em Riobaldo o primeiro plano da narrativa, a voz antes sufocada é aquela que agora tece suas confissões. Da memória histórica vazada pelo narrador onisciente passamos à memória constituída pelo tom pessoal, parcial, ambíguo. Da inteireza da voz forte do narrador alencariano, passamos à voz com um foco subjetivo, hesitante, incapaz, portanto, 
de dar-nos os demais pontos de vista envolvidos no enredo. Com esse recurso, temos uma única certeza: o desconforto de Riobaldo, sua sensação de incompletude, de estar sempre fora do lugar.

\section{TAL QUAL?!}

Para finalizar nossas considerações, convém colocarmos mais um peso nessa aparente balança e retomar algumas considerações iniciais. Ao pensar o Brasil, Süssekind (1984) questiona a insistência de uma estética realista naturalista ao longo da história da literatura brasileira, problema articulado com uma constante necessidade de afirmar a nação brasileira e a brasilidade. Chama-nos atenção a ênfase da autora em um sistema forjado pelas semelhanças:

Por que Machado de Assis, o romance dos anos Vinte, sobretudo com Oswald de Andrade e sua ficção fragmentária, ou Guimarães Rosa, representam simples "surtos" individualizados em meio à continuidade de uma estética naturalista? Por que não formam um sistema? (SÜSSEKIND, 1984, 42, sic)

Süssekind descortina um sistema que só se estabelece na medida em que cria uma identidade com a obra anterior. A menção a uma exposição que não desse à historiografia uma coesão forjada entre textos similares ou que fazem parte de uma mesma linhagem de obras narrativas, como o regionalismo e o indianismo, e as reflexões acima propostas devem nos alertar para a formação de um sistema em que a resposta ao binômio tal - qual seja inesperada.

Em termos de núcleo familiar como fulcro para a trama, Memórias Póstumas de Brás Cubas (MPBC) anuncia um narrador protagonista bem nascido, membro da classe dominante, mas herdeiro de uma genealogia que é apresentada como forjada, talvez diversa de uma realidade histórica. Ainda assim, o personagem narrador aproveita todas as possibilidades que sua condição lhe oferece, desde a compra de uma prostituta ou da moral de uma senhora até um emprego aparente e um emplastro famoso graças à propaganda que fez do mesmo. Brás, principalmente, demonstra não possuir nenhum tipo de compromisso com seu próprio discurso. Sua volubilidade desloca seu ponto de vista sempre em favor próprio - de certa forma, essa atitude discursiva escorregadia evidencia o avesso da volubilidade - , de modo a fazer aparecer sua posição social e as falcatruas possíveis graças a ela, agora realçadas pela condição de defunto escritor. 
A voz narrativa inscreve-se em um mundo sobrenatural, sobrescritando a arrogância de classe da personagem. Sem que saibamos como, pois isso não nos é revelado, Brás escreveu um romance no além. Portanto, seu grande feito é mostrar-se como um defunto autor. A narrativa confessional, pela trajetória do personagem e pelo modo como narra, expõe uma unidade. A voz volúvel, maliciosa e arrogante é a identidade do personagem. Entretanto, trata-se de uma unidade em cuja essência não se encontra nenhum princípio ético, tão pouco uma condição digna.

Parece-nos que a dependência subserviente vivida por Isabel e, em certo momento, por Riobaldo encontra eco em Machado de Assis, na figura do clientelismo. Dona Plácida, por exemplo, precisa se sujeitar às atitudes de Brás para sobreviver. Mesmo a contragosto, auxilia a encobrir o adultério para poder sobreviver, aceitando passivamente as migalhas que lhe oferece Brás. Se analisássemos Dom Casmurro ou algum de seus contos, a galeria ganharia amplitude.

Voltando ao romance de um defunto autor, o único personagem que enfrenta a arrogância e o cinismo de Brás Cubas é Eugênia. A análise de Schwarz (2000) percebe que o único personagem digno e de força moral de $M P B C$ é Eugênia, figura que desaparece rapidamente do enredo. O desenlace entre Eugência e Brás Cubas demonstra que, sob o ponto de vista desse narrador, descendente de tanoeiros alçado à classe dos poderosos, "inadmissíveis são a dignidade e o direito dos pobres" (SCHWARZ, 2000, p.102). Schwarz demonstra ainda que a Brás cabe a última palavra, de injúria, pois ele narra o episódio como "membro conspícuo da classe dominante, cujo ponto de vista a narrativa adota de maneira maliciosamente incondicional" (2000, p.103). Esse tom de uma indiferença ética das Memórias combate o sentimento moral e acusa, por meio de personagens como Eugênia e Dona Plácida, a passividade frente à opressão.

Ao passo que Isabel não pode se movimentar na sociedade em que se encontra, Riobaldo usufrui de uma gama imensa de papéis sociais, ciente de que apenas isso lhe é possível. Isabel, personagem cuja relevância se deve apenas por fazer um contraponto a Cecília, aparece imóvel em uma estrutura que lhe cobra inclusive a vida pelo direito de escolher a quem amar. Riobaldo, apesar da errança, permanece marcado por um sentimento inesgotável de travessia, sem conseguir internalizar o sertão em que vive, ainda dependente dos conselhos de Quelemém para convencer-se das afirmações de que precisa para permanecer onde e como está. Sua voz exterioriza angústias que Isabel sequer poderia cogitar, embora se alie à jovem mestiça: nem Riobaldo nem Isabel pertencem a uma família ao estilo 
dos Mariz e nenhum dos dois chega a sentir-se pertencente a um lugar, ou seja, não sabem qual é, de fato, sua identidade.

Brás Cubas, por sua vez, oferece-nos o ponto de vista da classe dominante, mas com uma vantagem sobre outros romances com o mesmo tema: o defunto autor. Na linhagem de personagens com que nos deparamos, a desfaçatez e a volubilidade de Brás revelam a certeza de quem se coloca acima dos demais, de quem usufrui da impunidade, situação confirmada pela façanha de escrever um romance no além. Mas sua identidade sofre um processo semelhante à de Riobaldo e Isabel. Apesar de ter uma família, Brás, como os dois personagens, não possui um lugar social claramente constituído em sua história. A genealogia de Brás vem pontuada por "saltos" que colocam em dúvida os meios pelos quais sua família ascende à posição que ocupa no momento representado pela narração. Paralelamente, a afirmação genealógica de Brás Cubas e o tom de sua narração confessam seu cinismo e sua falta de dignidade, qualidades que assomam frente a personagens socialmente oprimidos como Dona Plácida, personagens oportunistas como Marcela, ou ainda personagens moralmente enfraquecidos, como Virgília. Assim, dos três personagens analisados, Brás Cubas, o defunto autor de genealogia algo obscura, apresenta-se como aquele que conhece o lugar de onde fala, já que reconhece a que mundo pertence e sabe como se mantém nele. Mas, sintomaticamente, o legado de Brás Cubas, o saldo positivo de sua existência, é o fato de não ter tido filhos: "- Não tive filhos, não transmiti a nenhuma criatura o legado de nossa miséria.” (ASSIS, 1994, p.639)

Os três romances aliam memória e narrativa. Alencar recupera um ato de fundação da nação brasileira e, para isso, seu texto caminha em direção à lenda, como evidenciam a história de Tamandaré e o dilúvio. Rosa, ao recriar uma fala próxima a do homem do sertão, aproveita essa ilusão e coloca Rioabldo em uma trajetória que vai do caso e da lenda ao processo histórico de um país em que jagunços se transformaram em políticos ou em fazendeiros, sem preocupações relativas a um passado de mortes. Aliás, lembramos que o narrador rosiano aproxima-se de Brás Cubas se considerarmos o primeiro caso narrado por Riobaldo, o caso do bezerro com máscara de cachorro. Místico e temente, Riobaldo não apenas credita valores ao sobrenatural como abre a história de sua vida com a narração de um acontecimento espetacular. Machado, por sua vez, coloca em cena um narrador em um estado maravilhoso, situação que faz esmaecer a credibilidade cuja ironia e volubilidade reafirmam a dúvida quanto à veracidade do narrado, embora percebamos claramente o lugar de onde fala esse narrador-personagem. 
Da historiografia brasileira, coletamos três romances. Procuramos relacionar a ilha Machado de Assis a uma linhagem de personagens e narradores que poderiam iluminar a narração de nossa história da literatura. Dos três autores em questão, Machado e Rosa costumam receber um destaque como autores que inovaram a literatura brasileira. Entretanto, vistos apenas pelo viés estético, esses autores costumam estar dissociados, colocados em pontos opostos de um sistema de representação, ou em uma visão que opõe regionalismo e urbanismo.

Por outro lado, embora hoje muito criticado pela idealização de seus protagonistas, Alencar parece não apenas ter iniciado uma gama de representações em que buscou representar a cor local, como deu origem a uma linhagem de personagens em que o índio e o brasileiro olham não para a cruz, mas para a família (CUNHA, 2006, p.120), para um núcleo que aparece, em sua primeira representação da gente da terra, cindido e socialmente rechaçado.

\section{Referências}

ALENCAR, José de. O Guarani. 5. ed. São Paulo: Melhoramentos, [sem data].

ASSIS, Machado de. Obra completa. Rio de Janeiro: Nova Aguilar, 1994.

AUERBACH, Erich. Mimesis. São Paulo: Perspectiva, 1976.

BARBOSA, Frederico; BELETTI, Sylmara. Iracema de José de Alencar. Disponível em: <http://fredb.sites.uol.com.br/iracema.html>. Acesso em: out. 2006.

BLOOM, Harold. O cânone ocidental: Os livros e a escola do tempo. Rio de Janeiro: Objetiva, 2001.

BOSI, Alfredo. História concisa da literatura brasileira. São Paulo: Cultrix, 2006

BENJAMIN, Walter. O narrador. In: Magia e técnica, arte e política. São Paulo: Brasiliense, 1994.

CATROGA, Fernando. Recordação e esquecimento. In: Memória, história e historiografia. Coimbra: Editorial, 2001.

CASTRO, Ana Lúcia S. O papel social do museu: uma proposta de discussão. Texto apresentado na mesa redonda Nova museologia: papel político e social do museu, Santiago, Chile, 1992.

CUNHA, Eneida Leal. Estampas do imaginário: literatura, história e identidade cultural. Belo Horizonte: Ed. UFMG, 2006. 
GINZBURG, Carlo. O queijo e os vermes. São Paulo: Companhia das Letras, 2006.

ROSA, João Guimarães. Obra completa. Rio de Janeiro: Nova Aguilar, 1994.

ROSENFIELD, Kathrin. Os descaminhos do Demo - Tradição e ruptura em Grande sertão: veredas. São Paulo: Imago/EDUSP, 1993.

SANTIAGO, Silviano. Liderança e hierarquia em Alencar. In: Vale quanto pesa. Rio de Janeiro: Paz e Terra, 1982.

SCHWARZ, Roberto. Um mestre na periferia do capitalismo. São Paulo: Duas Cidades; Ed. 34, 2000.

SÜSSEKIND, Flora. Tal Brasil, qual romance? Rio de Janeiro: Achiamé, 1984.

STEGAGNO-PICCHIO, Luciana. História da literatura brasileira. Rio de Janeiro: Nova Aguilar, 2004. 